Journal of Engineering and Applied Sciences 14 (20): 7442-7447, 2019

ISSN: 1816-949X

(C) Medwell Journals, 2019

\title{
Earned Value Management for Ship Repair Project
}

\author{
Silvianita, Fadel Muhammad, Daniel M. Rosyid and Wimala Dhanista \\ Department of Ocean Engineering, Faculty of Marine Technology, \\ Institut Teknologi Sepuluh Nopember, Surabaya, Indonesia
}

\begin{abstract}
Vessel repairs are activities that are periodically planned in accordance with the requirements or regulations of the classification body and government as well as unforeseeable or unexpected work during the vessel during operation. In the process of ship repair often there are factors that cause changes between the initial plan and the realization that occurred in the field. One of the factors that becomes the benchmark of success on a project is the time and cost of workmanship. This study will analyze the project performance based on time and cost factors using Earned Value Analysis (EVA) method. This concept combines elements of schedule, cost and job performance (physical progress of current conditions in the field), it will be useful to identify how the cost and time estimation to complete a project. The results of the analysis shows that the concept of earned value analysis is the time estimation to be 5 weeks faster than the plan and cost estimation becomes more efficient Rp. 5,302,573,482.00. The estimated performance index of the plan against the completion of the project is 1.00 which means the performance index is constant.
\end{abstract}

Key words: Cost, earned, repair, vessel, value, performance index

\section{INTRODUCTION}

Vessel repairs are activities that are periodically planned in accordance with the requirements or regulations of the classification body and government and unforeseeable or unexpected work during the vessel during the operation. In SOLAS 1974/1978 it was affirmed that all ships from IMO countries should implement "Ship Maintenance and Repair". In the process of ship repair often there are factors that cause changes between the initial plan and the realization that occurred in the field. One of the factors that becomes the benchmark of success on a project is the time and cost of workmanship. If the project does not have human resources, material costs or good tools, the work schedule may be late and the costs incurred for work on the project become swollen (Barrie, 1995; Gray and Larson, 2008). Therefore, an analysis is needed, so that, prevention can be done in order to achieve a success value of the project (Cleland, 1991).

The analysis used in this study uses the concept of "Earned Value Analysis (EVA)". The concept is used for prevention to be achieved in order to achieve a value of success. In this concept combine elements of schedule, cost and job performance (physical progress of current conditions in the field), so, it can know how the cost and time estimates to complete a project. In addition, the benefits of using this method can also be used to detect as early as possible in the event of any cost swings or delays that may occur in the implementation of the project. The other useful of this method is the parties involved in this project can be able to overcome the obstacles that may affect the course of project activity.

Literature review: The flow of research on this study is done based on the following stages. The first stage is the determination of the background and the formulation of the problem which is then followed by literature study. The literature study used is the study of ship repair and the study of the concept of earned value analysis.

Earned value management system has been used widely in various projects namely electrical, civil, construction, ship and also NASA project (Wilson, 2013; Czemplik, 2014; Hanna, 2011; Batselier and Vanhoucke, 2015; Kwak and Anbari, 2012.

\section{MATERIALS AND METHODS}

Data collection based on existing ship repair project data in the field. The data which are required includes:

- Budget plan

- Project time schedule

- Progress report

- Actual Cost (AC)

Corresponding Author: Silvianita, Department of Ocean Engineering, Faculty of Marine Technology, Institut Teknologi Sepuluh Nopember, Surabaya, Indonesia 
Data analysis: At this step it will begin by analyzing the performance of projects in the form of Planned Value (PV), Earned Value (EV) and Actual Cost (AC). After obtained the three indicators are continued by analyzing the variant in the form of Cost Variance (CV) and Schedule Variance (SV).

Analysis of cost and time estimates: At this stage there are 2 indicators that are going to be evaluated namely cost and time. Cost and time will be useful to derive a decision making for ship repair. The procedure for decision making has been explained by Silvianita et al. (2013), Silvianita et al. (2018).

Cost estimation analysis: At this stage will be an analysis of costs. The first thing to do is to analyze the Cost Performance Index (CPI). The CPI serves to ascertain whether in a particular review period whether the cost incurred exceeds or less than the planned budget. After that Estimate at Completion Calculation (EAC) is used to find out how the estimated cost to be issued at the end of the project.

Time estimation analysis: At this stage will be an analysis of time. The first thing to do is calculate the Earned Schedule (ES). ES function to know the value of a project achieved in units of time (Henderson, 2003; Lipke, 2003). The next step is to perform the Schedule Performance Index (SPI) analysis. SPI serves to determine whether during a particular review period whether progress of project work that has been completed to a certain period is faster or slower than the planned time. The next step is to calculate the Independent Estimate of (Project) Duration (ED) (Henderson, 2003). IED serves to determine the approximate date of completion of the project undertaken by the contractor.

Calculate To Complete Performance Index (TCPI): At this stage of the estimated cost and time will be calculated To Complete Performance Index (TCPI). TCPI is the probability index value of an estimate. This index is used to increase confidence in reporting assessment on the remainder of the work. The result of TCPI will be known whether the performance on the project has increased work, decreased work or constant.

\section{RESULTS AND DISCUSSION}

Project overview: The first phase warship repair project is a project undertaken by PT. XXX as the shipyard and the Navy as the owner of the ship. This project runs from October 2016 until November 2017 for a total cost of Rp. 110, 389, 133, 166.00 (Fig. 1 and Table 1).

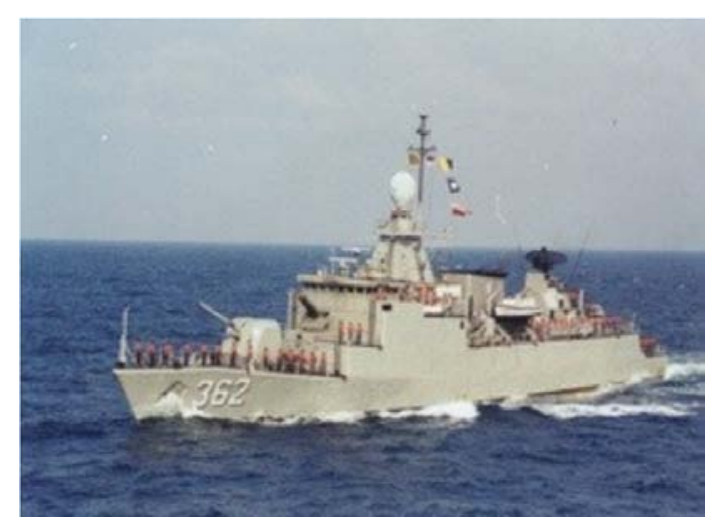

Fig. 1: Warship

Table 1: Warship data

\begin{tabular}{ll}
\hline Main size & Values \\
\hline Length Over All (LOA) & $113.42(\mathrm{~m})$ \\
Breadth (B) & $12.51(\mathrm{~m})$ \\
Draft (T) & $4.57(\mathrm{~m})$ \\
Speed (Vmax) & $30($ Knot) \\
DWT & 1450 (Ton) \\
Ship crew & 82 (Crews) \\
\hline
\end{tabular}

Table 2: Reparations of warship phase I budget plan cost

\begin{tabular}{llc}
\hline Work description & Cost & Percentage (\%) \\
\hline Renting of tugboat & Rp. 46,814,981.00 & 0.04 \\
Docking & Rp. 126,400,448.00 & 0.11 \\
Engine room reparation & Rp. 203,645,166.00 & 0.18 \\
Propeller reparation & Rp. 227,052,657.00 & 0.21 \\
Inclining test & Rp. 114,696,703.00 & 0.10 \\
\hline
\end{tabular}

Table 3: Progress per review period

\begin{tabular}{lc}
\hline Review period & Total progress (\%) \\
\hline 31 October 2016 & 03.19 \\
30 November 2016 & 09.47 \\
31 December 2016 & 11.19 \\
31 January 2017 & 33.00 \\
15 February 2017 & 33.16 \\
31 May 2017 & 67.13 \\
\hline
\end{tabular}

Budget plan cost: The budget plan contains the description and type of work, the price per job type, the weight per work type and the total cost amount. On this project there are 81 items of work with the project cost of Rp. 110,389,133,166.00. For the example renting of tugboat item with cost of Rp. $46,814,981.00$, then, divided by total cost, so that, we get percentage equal to $0.04 \%$. Then, the calculation is continued for other work items (Table 2 and 3 ).

Progress report: Progress reports are data that contains the work description, the percentage of progress and the total percentage of the progress at the time of progress report being made. At the time of data collection, it has been done 6 progress reports. 
Table 4: Time schedule

\begin{tabular}{lccc} 
Work description & Percentage (\%) & $\begin{array}{c}\text { Duration } \\
\text { (weeks) }\end{array}$ & $\begin{array}{c}\text { Percentage for } \\
\text { each week (\%) }\end{array}$ \\
\hline Renting of tugboat & 0.04 & 1 & 0.04 \\
Docking & 0.11 & 4 & 0.029 \\
Engine room reparation & 0.18 & 3 & 0.061 \\
Propeller reparation & 0.21 & 5 & 0.041 \\
Inclining test & 0.10 & 1 & 0.10 \\
\hline
\end{tabular}

Table 5: Planned Value (PV)

\begin{tabular}{lcl}
\hline Review period & Total plan percentage (\%) & PV \\
\hline 31 October 2016 & 00.46 & Rp. 503,374,447.00 \\
30 November 2016 & 01.22 & Rp. 1,351,162,990.00 \\
31 December 2016 & 21.28 & Rp. 23,487,495,864.00 \\
31 January 2017 & 34.65 & Rp. 38,253,146,316.00 \\
15 February 2017 & 47.51 & Rp. 52,442,565,493.00 \\
31 May 2017 & 89.86 & Rp. 99,193,467,281.00 \\
\hline
\end{tabular}

Time schedule analysis: This time schedule is based on the planned work schedule in the repair list and the percentage of each job in budget plan. After that can be made time schedule that contains percentage planned per time unit.

For the example for docking carried out for 4 weeks with a percentage of $0.11 \%$, then the percentage of work to be done each week is $0.029 \%$ (Table 4).

Once we get the weight per week, the percentage for each week is plotted in accordance with the schedule that has been planned by the contractor. Then, for each review period summed up to the date of the review, so that, the accumulation percentage is gained per each review period.

Planned Value (PV): PV is the budget that allocated based on the work plan that has been prepared against time. PV is calculated from the accumulated budget planned for the warship reparation in a given period. PV can be obtained with this following formula:

$$
\text { PV }=\text { Percentage plan }(\%) \times \text { Budget cost }(\mathrm{Rp})
$$

For the example for the review period on 31 October 2016 has a plan progress of $0.46 \%$ and then multiplied by budget plan cost so the PV is Rp. $503,374,447.00$ below is the calculation Table 5. Figure 2 shows.

Earned Value (EV): $\mathrm{EV}$ is received from the completion of work for a certain period of time (Pmbok, 2013). This EV is calculated based on the accumulation of completed work. $\mathrm{EV}$ can be obtained with this following formula:

$$
\text { EV }=\text { Percentage of Progress }(\%) \times \text { Budget Cost }(\mathrm{Rp})
$$

For the example for the review period on 31 October 2016 has a percentage of progress equal to $3.19 \%$ and then, multiplied by budget plan cost, so, the EV is Rp. 3 , $523,361,932.00$, Table 6 . Figure 3 shows the EV curve from October until June.
Table 6: Earned value

\begin{tabular}{lcc}
\hline Review period & Total progress percentage (\%) EV \\
\hline 31 October 2016 & 03.19 & Rp. 3,523,361,932.00 \\
30 November 2016 & 09.47 & Rp. 10,454,551,390.00 \\
31 December 2016 & 11.19 & Rp. 12,347,957,547.00 \\
31 January 2017 & 33.00 & Rp. 36,431,840,821.00 \\
15 February 2017 & 33.16 & Rp. 36,608,747,190.00 \\
31 May 2017 & 67.13 & Rp. $74,101,200,525.00$ \\
\hline
\end{tabular}

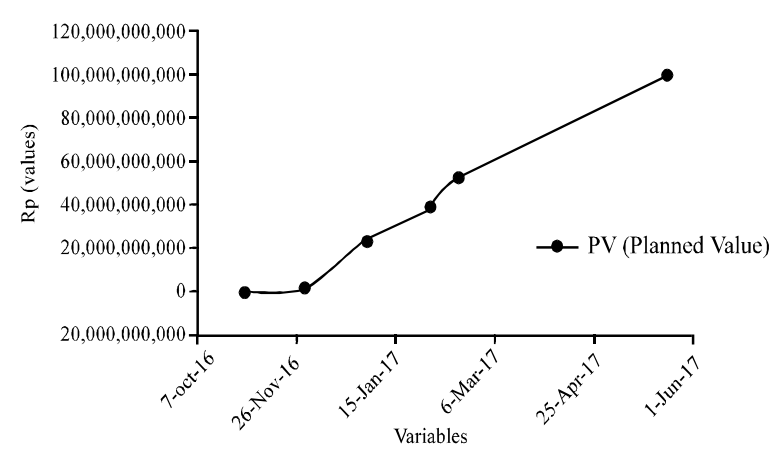

Fig. 2: PV curve

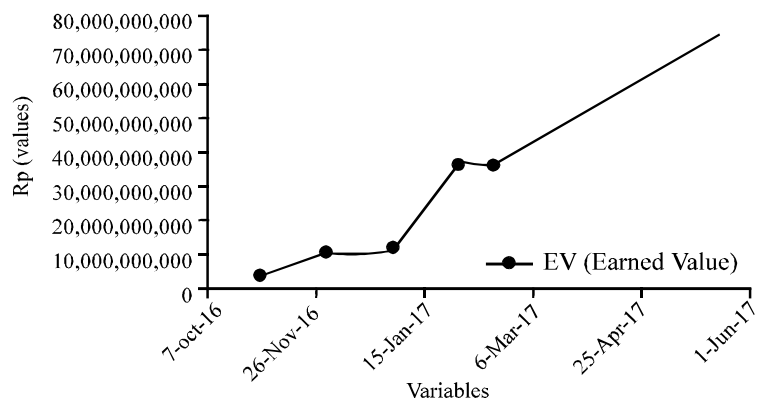

Fig. 3: EV curve

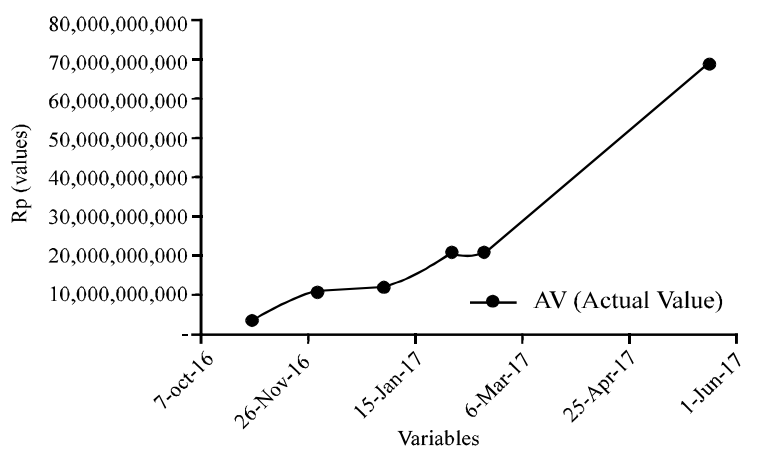

Fig. 4: AC curve

Actual cost: $\mathrm{AC}$ is a representation of the total cost incurred to complete the work within a certain period Table 7. Figure 4 hows the AC curve from October until June.

Schedule Variance (SV): SV is used to calculate the deviation between PV and EV. SV is obtained by the following formula: 


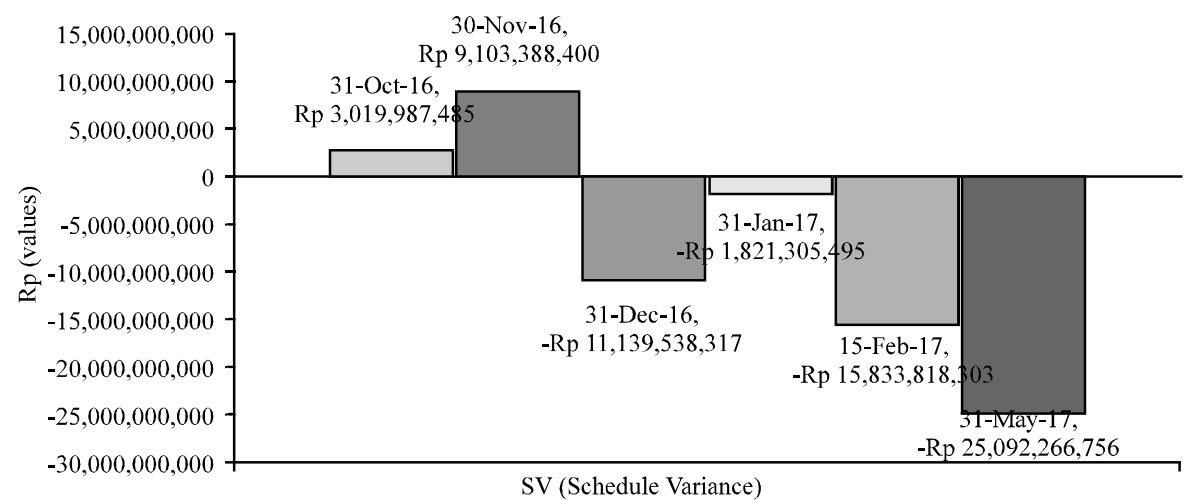

Fig. 5: SV bar graph

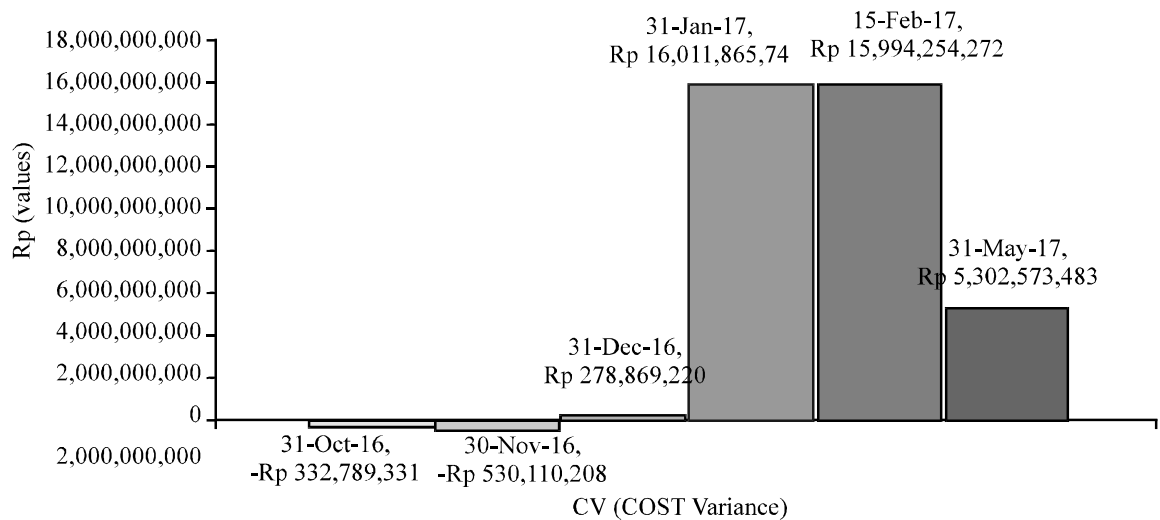

Fig. 6: CV bar graph

Table 7: Actual cost

\begin{tabular}{ll}
\hline Review period & Actual cost \\
\hline 31 October 2016 & Rp. $3,856,151,262.00$ \\
30 November 2017 & Rp. $10,984,661,597.00$ \\
31 December 2016 & Rp. $12,069,088,327.00$ \\
31 January 2017 & Rp. $20,419,975,073.00$ \\
15 February 2017 & Rp. $20,614,492,918.00$ \\
31 May 2017 & Rp. $68,798,627,041.00$ \\
\hline
\end{tabular}

Table 8: SV calculation

\begin{tabular}{ll}
\hline Review period & Schedule variance \\
\hline 31 October 2016 & Rp. $3,019,987,485.00$ \\
30 November 2016 & Rp. $9,103,388,400.00$ \\
31 December 2016 & -Rp. $11,139,538,317.00$ \\
31 January 2017 & -Rp. $1,821,305,495.00$ \\
15 February 2017 & -Rp. $15,833,818,303.00$ \\
31 May 2017 & -Rp. $25,092,266,756.00$ \\
\hline
\end{tabular}

$$
\mathrm{SV}=\mathrm{EV}-\mathrm{PV}
$$

For the example in the period of review on 31 October 2016 known PV for Rp. 503,374, 447.00 and EV for Rp.3, $523,361,932.00$, so, $\mathrm{SV}$ is obtained amount to Rp. $3,019,987,485.00$. Then, it will be calculate in the same way for the next review period. The SV calculation Table 8. Figure 5 shows the SV bar graph as follows:
Table 9: CV calculation

\begin{tabular}{ll}
\hline Review period & Cost variance \\
\hline 31 October 2016 & -Rp. $332,789,331.00$ \\
30 November 2016 & -Rp. $530,110,208.00$ \\
31 December 2016 & Rp. $278,869,220.00$ \\
31 January 2017 & Rp. $16,011,865,747.00$ \\
15 February 2017 & Rp. $15,994,254,272.00$ \\
31 May 2017 & Rp. $5,302,573,483.00$ \\
\hline
\end{tabular}

Cost Variance (CV): CV is the difference between earned upon completion of a particular job and the actual costs incurred during the project execution. CV obtained with the following formula:

$$
\mathrm{CV}=\mathrm{EV}-\mathrm{AC}
$$

The period of review 31 October 2016 the EV is known of Rp. 3,523, 361,931.00 and AC for Rp. 3,856,151, 262.00, so, CV is obtained amount to-Rp. 3,019,987,485.00. Then it will be calculated in the same way for the next review period. CV table calculations Table 9. Figure 6 shows the CV bar as follows.

Earned Schedule (ES) calculation: ES is the magnitude of a project achieved in units of time, obtained from all work 
Table 10: ES calculation

\begin{tabular}{lc}
\hline Review period & Earned schedule (weeks) \\
\hline 31 October 2016 & 7.00 \\
30 November 2016 & 15.74 \\
31 December 2016 & 8.50 \\
31 January 2017 & 12.88 \\
15 February 2017 & 15.88 \\
31 May 2017 & 18.46 \\
\hline
\end{tabular}

Table 11: SPI calculation

\begin{tabular}{lc}
\hline Review period & Schedule performance index \\
\hline 31 October 2016 & 1.75 \\
30 November 2016 & 1.97 \\
31 December 2016 & 0.71 \\
31 January 2017 & 0.80 \\
15 February 2017 & 0.88 \\
31 May 2017 & 0.58 \\
Average & 1.11 \\
\hline
\end{tabular}

that is being done or has been completed cumulatively (Henderson, 2003; Lipke, 2003). ES obtained with the following formula:

$$
\mathrm{ES}=\mathrm{C}+\mathrm{I}
$$

Where:

$\mathrm{I}=\left(\mathrm{EV}-\mathrm{PV}_{\mathrm{c}}\right) /\left(\mathrm{PV}_{\mathrm{c}+1}-\mathrm{PV}_{\mathrm{c}}\right)$

For the example, during the period of review 31 October 2016 known C for 0 weeks, EV known for Rp. 3 , $523,361,932.00$, PVc known for Rp. 0 and PVc +1 known for Rp. 503,374,447.00, so, ES is obtained in that review period 7.00 weeks. Then it will be calculated the same way for the next review period. Table 10 of ES calculations.

Schedule Performance Index (SPI) calculation: SPI is a representation of how the efficiency of a project's performance is reviewed from the schedule (9). SPI is obtained with the following formula:

$$
\mathrm{SPI}=\frac{\mathrm{ES}}{\mathrm{AT}}
$$

For the example, during the review period of 31 October 2016 it was known that ES for 7.00 weeks and AT known for 4.00 weeks, so, SPI is obtained in that review period 1.75. Then it will be calculated in the same way for the next review period. SPI Table 11 calculations. Figure 7 shows SPI graph.

From the above SPI calculations show that if the SPI has more than 1 result then the project performance is faster than the schedule of the plan, otherwise, if the result is $<1$ then the project performance is slower than the planned schedule.

Cost Performance Index (CPI) calculation: CPI is a cost efficiency factor that has been incurred. CPI is obtained by the following formula:
Table 12. CPI calculation

\begin{tabular}{lc}
\hline Review period & Cost performance index \\
\hline 31 October 2016 & 0.91 \\
30 November 2016 & 0.95 \\
31 December 2016 & 1.02 \\
31 January 2017 & 1.78 \\
15 February 2017 & 1.78 \\
31 May 2017 & 1.08 \\
Average & 1.25
\end{tabular}

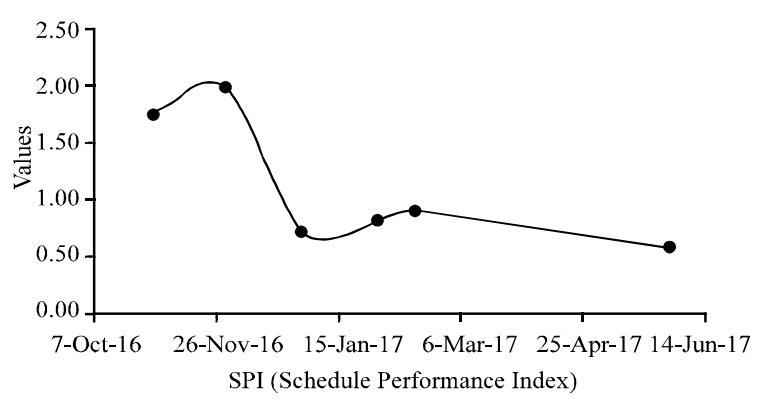

Fig. 7: SPI graph

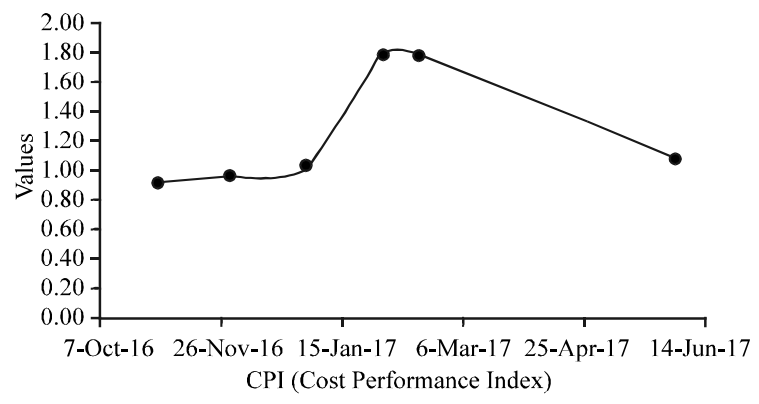

Fig. 8: CPI graph

$$
\mathrm{CPI}=\frac{\mathrm{EV}}{\mathrm{AC}}
$$

For the example, during the review period of 31 October 2016 it was known that EV w for Rp.3, 523,361, 931.00 and AC known for Rp.3, 856,151,262.00, so, CPI is obtained that review period 0.91 . Then it will be calculated in the same way for the next review period. CPI Table 12 calculation. Figure 8 shows CPI graph.

Project completion duration: Independent Estimate of (project) Duration (IED) is the total estimated time required by the contractor to complete the project (Henderson, 2003). IED is obtained by the following formula:

$$
\mathrm{IED}=\frac{\mathrm{PD}}{\mathrm{SPI}}
$$

Since, the SPI in each review period is always changing then the average SPI is used. So, IED obtained by 47.53 weeks. Then to get the remaining time 
estimates for project completion by reducing the IED with AT in the last review of the 32 nd week, so that, the estimated time remaining for project completion for 15.54 weeks or rounded to 16 weeks.

The estimated completion of the first phase warship repair project is 5 weeks faster than the time schedule which is at the 4th week of September 2017.

Estimated cost of completion of the project: Estimate at Completion (EAC) is the total cost estimate at the end of the project. EAC obtained with the following formula:

$$
\mathrm{EAC}=\mathrm{AC}+(\mathrm{BAC}-\mathrm{EV})
$$

In the calculation of total estimation at the end of the project using the $\mathrm{AC}$ and $\mathrm{EV}$ indicator in the last review period on 31 May 2017 with AC known for Rp. 68,798, 627, 041.00 andEV known for Rp. 74,101,200,525.00, so, EAC is obtained for Rp.105,086,559,684.00. Then to get the remaining cost estimate for project completion by reducing $\mathrm{EAC}$ with $\mathrm{EV}$ in the last review period of $\mathrm{Rp}$. $68,798,627,041.00$, so that, the estimated cost remaining for project completion is Rp. $36,287,932,642.00$ or rounded to Rp.36,300,000,000.00. The estimated completion of the warship repair project phase I become more efficient at Rp.5,302,573,482.00.

Estimated plan for project completion: The Complete Performance Index (TCPI) is the probable index of a forecast. This index is used to increase confidence in reporting assessment on the remainder of the work. TCPI is obtained by the following formula:

$$
\mathrm{TCPI}=\frac{(\mathrm{BAC}-\mathrm{EV})}{(\mathrm{EAC}-\mathrm{AC})}
$$

In the calculation of TCPI using EV and AC on the last review on 31 may 2017 with $\mathrm{EV}$ amount of Rp. 74,101,200,525.00 and AC amount of Rp. 68,798,627,042.00. $\mathrm{BAC}$ is known from the data that is Rp. $110,389,133,166.00$ and EAC obtained from the previous calculation of Rp. $101,927,063,533.00$, so, TCPI is obtained 1.00 . With TCPI on the project showing the number of 1.00 , it is known that the index performance completion of warship repair project is constant.

\section{CONCLUSION}

Based on the analysis that has been done, the things that we can be concluded from this study are: the average performance index against the schedule is 1.11 ; it shows that the average schedule performance is good or in other words faster. Otherwise, the average performance index of the cost of 1.25, it shows that the average cost performance is good or in other words savings occur.
The approximate completion of time for completion of the remaining $1 \mathrm{~s}$-phase repair project is to 16 weeks which is on the 4th week of September 2017. The estimated completion of the first warship repair project phase 1 is 5 weeks sooner than the time schedule. Otherwise, the estimated cost of completion of the completion of the remaining phase 1 repair project of the stages is Rp.36.300.000.000,00. The estimated cost of completion of the warship repair project phase 1 become more effective Rp. 5,302,573,482.00 from the initial budget cost plan.

The estimated achievement estimation of the project Completion Plan (TCPI) in the first phase of the warship repair project shows the figure of 1.00 , so, it is known that the completion achievement index in the warship repair project phase 1 is constant.

\section{REFERENCES}

Barrie, D.S., 1995. Project Management Strategic Design and Implementation. McGraw Hill Inc., Singapore,.

Batselier, J. and M. Vanhoucke, 2015. Empirical evaluation of earned value management forecasting accuracy for time and cost. J. Constr. Eng. Manage., 141: 1-13.

Cleland, D.I., 1991. Project Management Strategic Design and Implementation. 3rd Edn., McGraw Hill, Singapore.

Czemplik, A., 2014. Application of earned value method to progress control of construction projects. Procedia Eng., 91: 424-428.

Gray, C.F. and E.W. Larson, 2008. Project Management The managerial Process. 4th Edn., McGraw Hill, New York.

Hanna, A.S., 2011. Using the earned value management system to improve electrical project control. J. Constr. Eng. Manage., 138: 449-457.

Henderson, K., 2003. Earned schedule: A breakthrough extension to earned value theory? A retrospective analysis of real project data. Measurable News, 1: 1323.

Kwak, Y.H. and F.T. Anbari, 2012. History, practices and future of earned value management in government: Perspectives from NASA. Project Manage. J., 43: 77 90.

Lipke, W., 2003. Schedule is different. Measurable News, $1: 31-34$.

Silvianita, M.F. Khamidi, Suntoyo and D.M. Chamelia, 2018. Methodology for Investigation of Risk Based Maintenance (MIRBA) for mobile mooring system. Res. J. Appl. Sci., 13: 26-33.

Silvianita, S., M.F. Khamidi and V.J. Kurian, 2013. Decision making for safety assessment of mobile mooring system. Jurnal Teknologi, 61: 41-52.

Wilson, B., M. Frolick and T. Ariyachandra, 2013. Earned value management systems: Challenges and future direction. J. Integr. Enterp. Syst., 2: 9-17. 